NASA Technical Memorandum 83660

AIAA-84-1184

\title{
Development of Dynamic Simulation of TF34-GE-100 Turbofan Engine with Post-Stall Capability
}

Susan M. Krosel

Lewis Research Center

Cleveland, Ohio

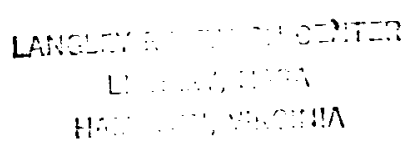

Prepared for the

Twentieth Joint Propulsion Conference cosponsored by the AIAA, SAE, and ASME Cincinnati, Ohio, June 11-13, 1984

\section{N/SN}


EITER:

17

ì $\quad$ I

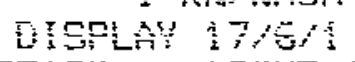

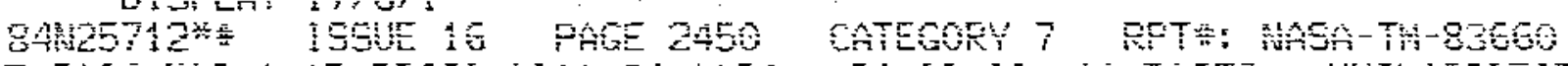
E-210A KWE DOSUHE:

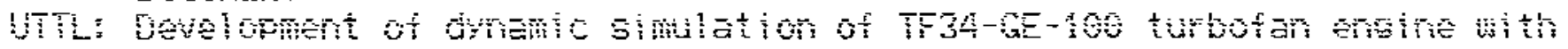

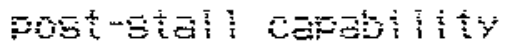

AUTH: A, TROSEL, S. H.

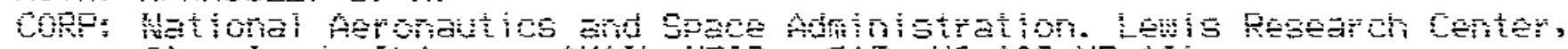

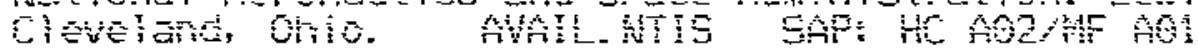

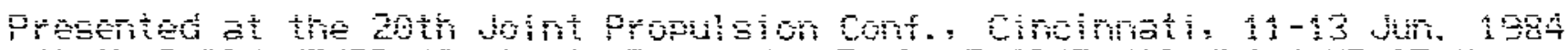

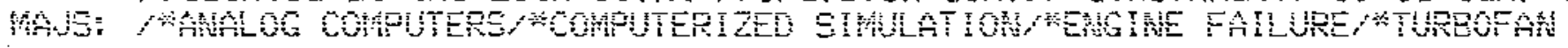
ENGIBES

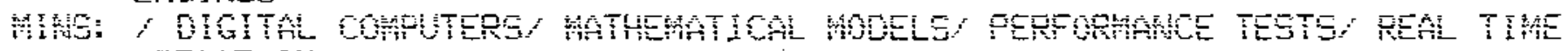
OPERATIOH

ABA: Authot 
AIAA-84-1184

Development of Dynamic Simulation of

TF34-GE-100 Turbofan Engine with

Post-Stall Capability

Susan M. Krosel, NASA Lewis Research

Center, Cleveland, $\mathrm{OH}$

\section{AIAA/SAE/ASME \\ 20th Joint Propulsion Conference \\ June 11-13, 1984/Cincinnati, Ohio}

$\sqrt{184-25712^{\#}}$ 
DEVELOPMENT OF DYNAMIC SIMULATION OF TF34-GE-100 TURBOFAN ENGINE WITH POST-STALL CAPABILITY

\author{
Susan M. Krose 1 \\ National Aeronautics and Space Administration \\ Lewis Research Center \\ Cleveland, Ohio 44135
}

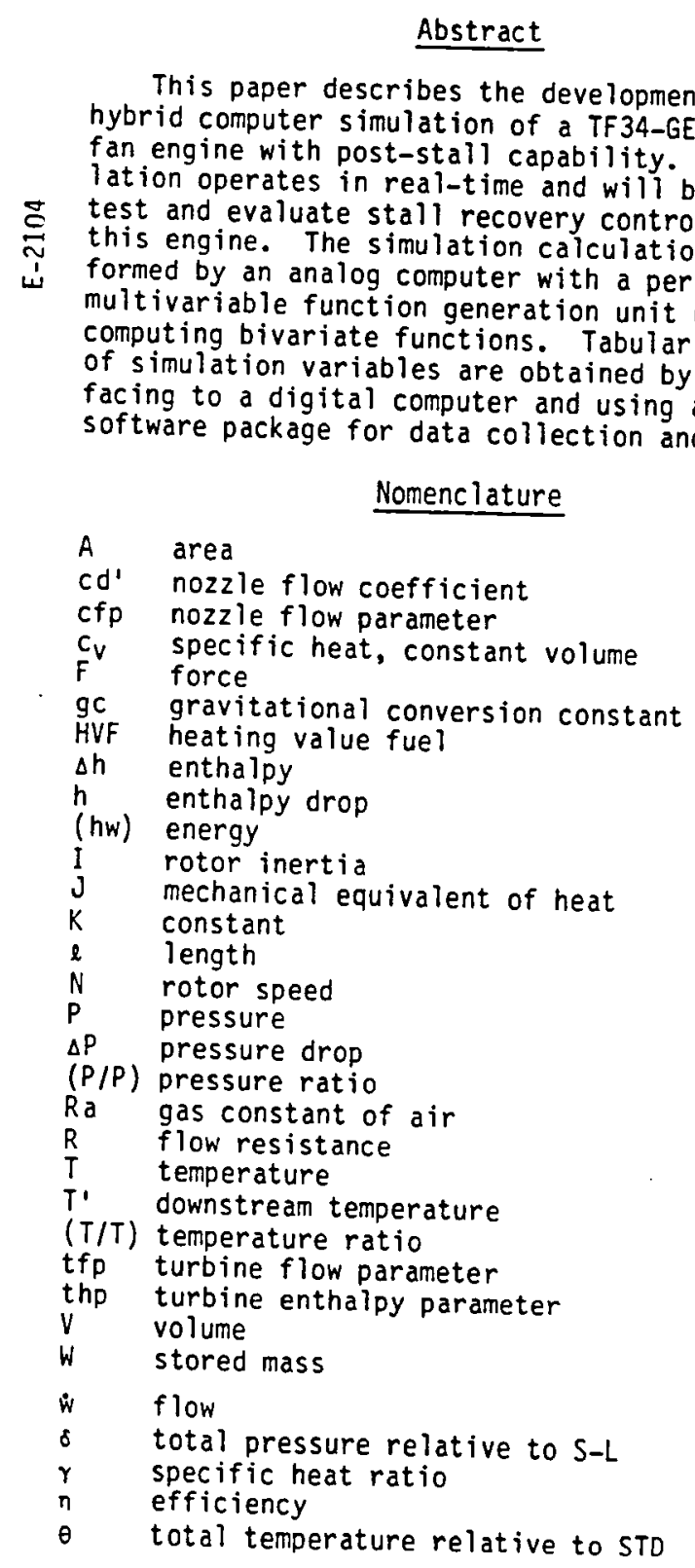

\section{Subscripts}

$\begin{array}{ll}\text { BLD } & \text { bleed } \\ \text { C } & \text { compressor } \\ \text { CB } & \text { combustor } \\ \text { FC } & \text { fan or compressor } \\ \text { FH } & \text { fan hub } \\ \text { FT } & \text { fan tip } \\ \text { I } & \text { inlet } \\ \text { N } & \text { nozzle }\end{array}$

TB turbine

$f$ fuel

i initial condition

in into volume

out out of volume

\section{Introduction}

The desire for increased performance from aircraft gas turbine engines has resulted in engine operation close to stall. Because of this, the possibility of engine stall has increased. In most instances of stall, there is a momentary change in the engine airflow pattern and a loss in thrust. Usually, the engine returns to its normal uperating condition without the need for corrective control action. This is a recoverable stall. However, in some cases, the engine fails to recover and settles at a stabie, low-thrust, operating point with low rotational speeds and high turbine temperatures. To restore power and prevent serious engine damage, the engine must be shut down and restarted. This is termed nonrecoverable or "hung" stall.

The reasons why some stalls are recoverable and others degenerate into nonrecoverable stalls are not fully known or understood. The NASA Lewis Research Center is conducting a research program to gain a better understanding of stall occurrence and to design and evaluate control strategies for stall recovery.

A necessary tool in the understanding of stall phenomena is a mathematical model of the engine dynamics. Such a model must accurately describe both the normal out-of-stall and the in-stall behavior of the engine. Previous work has been done 1 to develop a post-stall model/simulation of the General Electric TF34-GE-100 engine compression system. That simulation is capable of producing recoverable and nonrecoverable stalls, depending on the value of certain engine parameters. However, that simulation is limited to operation at fixed compressor and fan speeds since the engine turbine models and rotor dynamics are not included.

To evaluate control strategies for stall recovery, a simulation that can represent steadystate and dynamic engine performance over a full range of operating conditions (i.e., out-of-stall and in-stall) is required. Furthermore, if the simulation is to be used to validate actua? control system software and/or hardware, then the simulation must operate (i.e., solve the dynamic equations) in real time. Hybrid computer simulations have been shown to provide this real-time response while getaining a high degree of steadystate accuracy. 2

This oaper describes the formulation of a mathematical model and the development of a full 
range, real-time, hybrid computer simulation of the TF34-GE-100 turbofan engine.

The mathematical model of the out-of-stall engine performance was derived from the engine manufacturer's steady-state digital simulation of the engine. The in-stall model was based on the results of Greitzer's work.3-5 Many of the assumptions and techniques used to develop the overall hybrid simulation were based on earlier developments of real-time hybrid computer simulations of the Pratt and Whitney TF $30-P-3$ and F100-PW-100 augmented turbof an engines, $6-8$

The engine model was programmed to run on one of the NASA Lewis Research Center's two hybrid (analog and digital) computer systems. The bulk of the simulation calculations are performed on the analog computers. A peripheral multivariable function generation unit is used to evaluate the model's bivariate functions. The digital computer was interfaced through analog-to-digital converters (ADC's) and a custom software package was developed for data collection and display.

\section{Engine Description}

The TF34-GE-100 turbofan engine is designed and manufactured by the Aircraft Engine Group of the General Electric Company in West Lynn, Massachusetts. The TF34-GE-100 is a dual rotor, front fan, two stream, separated flow, high bypass ratio turbofan engine. A single inlet supplies airflow to a single stage fan. After leaving the fan, this airflow separates into two streams, one through the engine core; the other through the bypass duct. Since the TF34 has a high bypass ratio, the bulk of the airflow passes through the bypass duct and when exhausted, provides the major portion of engine thrust.

The core airflow passes through the compressor which has fourteen stages and variable stators. In the combustor, the air is mixed with fuel and burned, providing the hot gases to drive the turbines. The gas generator turbine drives the compressor. It consists of two air-cooled stages and is connected to the compressor by a hollow shaft. The fan turbine has four stages and drives the fan through a shaft concentric to the gas generator shaft.

The bypass duct airflow and core gas flow exhaust through separate nozzles. The exhaust nozzle areas are fixed and convergent. The core stream convergent nozzle is concentric to the bypass stream convergent nozzle. A schematic representation of the TF34-GE-100 turbofan engine is given in Fig. 1. Engine station identifications are also given.

\section{Mode 1}

The mathematical model of the TF34-GE-100 turbofan engine must represent steady-state and dynamic engine performance over a full range of operating conditions (i.e., out-of-stall and install). The model reported herein differs from previous models ${ }^{6-8}$ in that it provides for install operation. This model is based, to the extent possible, on data obtained from the engine manufacturer's steady-state digital simu-

lation.9 In some cases, other sources of
TF34 engine data were needed when developing models of specific components. Figure $2(\mathrm{~A})$ shows the computational flow in the model for norma? engine airflow. In Fig. $2(B)$, component models that must account for reverse flow or rich fuelair mixtures are noted.

For steady-state accuracy, wide range performance maps are included for the fan and compressor. To provide transient capability, fluid momentum, mass and energy storage and rotor inertias are included. Intercomponent volumes are assumed at engine locations where gas dynamics are considered important or necessary to avoid iterative calculations. Dynamic forms of the continuity and energy equations and the state equation are solved for stored mass, temperature and pressure in each volume. The effect of fluid momentum on engine dynamics is also considered in this simulation. The momentum equation is solved for flow in the fan tip, the fan hub and the compressor.

For flow reversal which may occur during stall, the source temperatures for the affected energy equations are switched from the norma? upstream temperatures to the temperatures within the particular volume. To avoid discontinuities in the corrected speed for the fan and compressor, the upstream temperature value is still used as the correcting temperature during reverse flow. These in-stall models for the inlet, fan, and compressor are based on the work reported in Ref. 1. Fan or compressor stall is detected when, for a specified corrected speed, airflow is less than the airflow at the stall line. To attain realtime response of this simulation and to minimize the number of analog components needed, some simplification of the basic aerothermodynamic relationships in the model was necessary. Fluid properties, such as specific heats and gas constants, were assumed to be constant (i.e., independent of temperature and fuel-air ratio) over the engine operating range. Additionally, the effect of fuel-air ratio on enthalpy in the turbine volumes was assumed negligible.

Descriptions of the individual component models follow. General forms of the equations are given.

$\underline{\text { Inlet }}$

The inlet is modelled as a pressure drop using the general equation form

$$
\dot{w}_{I}=\Delta P_{I} / R
$$

The inlet conditions are set as necessary to attain the desired fan inlet conditions. Volume dynamics for mass and energy storage are included. The forms for the energy and stored mass equations, used in this model, are

$$
\begin{gathered}
\frac{d}{d t}(W T)=\gamma *\left[\Sigma\left(\dot{w}_{\text {in }} * T_{\text {in }}\right)-\Sigma\left(\dot{w}_{\text {out }} * T\right)\right] \\
\frac{d}{d t}(W)=\Sigma \dot{w}_{\text {in }}-\Sigma \dot{w}_{\text {out }}
\end{gathered}
$$

where $\dot{w}_{\text {in }}$ denotes flow into the volume, $\dot{w}_{\text {out }}$ 
denotes flow out of the volume, $T$ in is upstream temperature, and $T$ is the temperature of the volume. The inlet pressure and temperature are calculated from the gas state equation

$$
P \star V=W * R a \star T
$$

During flow reversal in stall, the inlet acts as an energy sink. As discussed earlier, the reference temperatures change and hence, the form of the energy equation becomes

$\frac{d}{d t}(W T)=r *\left(\Sigma\left(\dot{w}_{\text {in }} \star T\right)-\Sigma\left(\dot{w}_{\text {out }} \star^{*} T^{\prime}\right)\right)$

where $T^{\prime}$ is the downstream temperature.

Fan

Overall performance maps are used to represent the out-of-state steady-state performance of the fan. There are separate maps for the fan tip and hub sections due to the radial pressures gradient that exist in the fan. The fan tip and fan hub pressure ratios, $(P / P)_{F T}$ and $(P / P)_{F H}$, are computed from bivariate functions of corrected total fan airflow and corrected fan speed. Corresponding fan discharge temperature ratios, $(T / T)_{F T}$ and $(T / T)_{F H}$, are calculated as linear functions of the respective pressure ratios. This avoids having to compute fan adiabatic efficiency and calculations involving exponentiation. From the $f a n$ tip and $f$ an hub pressure and temperature ratios, the fan tip and $f$ an hub pressures and temperatures, $\mathrm{PFT}_{\mathrm{F}} \mathrm{P}_{\mathrm{FH}}, \mathrm{T}_{F T}$, and $T_{F H}$ are calculated. Volume dynamics for the fan tip and hub volumes are included. The equations for the energy and stored mass, (WT)FT, WFT, (WT) FH, and WFH are similar in form to Eqs. (2) and (3) of the inlet. Energy contributed by shaft work is accounted for by the calculation of the fan discharge temperatures. Fan duct and compressor inlet pressure and temperature conditions are calculated from the gas state Eq. (4). Radial crossflow in the engine gooseneck, between the fan tip and hub sections is assumed to be proportional to the pressure difference. Zero crossflow is assumed at the design steady-state point. Additionally, flow dynamics are considered for the fan tip and fan

hub flows, $\dot{w}_{F T}$ and $\dot{w}_{F H}$ by use of fluid momentum equations. The general form for the momentum equation is

$$
\dot{w}=(1 / \ell) \int_{0}^{t}(\Delta(P * A)+F) d t+\dot{w}_{j}
$$

The in-stall fan model is based on the model of Ref. 1. The stalled energy equations for the fan tip and fan hub volumes provide for changes in the reference temperatures as was done for the Inlet volume. The form of these energy equations is similar to Eq. (5) of the Inlet.

The stalled pressures and temperatures of the $f$ an are calculated from the phi-psi relationship given in Ref. 1. This simplifies the fan stall model by avoiding bivariate map evaluations during stall. Reversed and forward fan flow during stall is accounted for in these equations.

\section{Compressor}

As with the fan, the out-of-stall steady-state performance of the compressor is represented by an overall performance map. Inputs to this bivariate map are corrected compressor flow and corrected compressor speed. The output of the map is the compressor pressure ratio, (P/P)C. Compressor temperature ratio, $(T / T)_{C}$, is fit as a function of the pressure ratio. Volume dynamics for the energy and stored mass, $(W T)_{C}$ and $W_{C}$, are included. These are similar in form to Eas.

(2) and (3) of the Inlet. Compressor flow, $w_{c}$, is calculated by a momentum equation similar to Eq.

(6) given in the Fan.

As for the fan, the in-stall model is based on the compressor model contained in Ref. 1. The stalled form for the compressor energy equation reflects the changes in reference temperatures as shown in Eq. (5) for the Inlet. A phi-psi relationship from Ref. 1 calculates the stalled pressure and temperature for both reversed and forward compressor flow during stall.

Bleeds

Compressor discharge bleed is used for turbine cooling. The turbine in-flow bleeds are modelled simply as constant proportions of compressor flow. The general equation form is

$$
\dot{w}_{B L D}=K_{B L D}{ }^{\star} \dot{w}_{C}
$$

Combustor

Combustor airflow is calculated directly from the pressure drop across the combustor given by

$$
\dot{w}_{C B}=\sqrt{P_{C B} \star(\Delta P){ }_{C B} /\left(K_{C B}{ }^{*} T_{C B}\right)}
$$

An algebraic energy equation replaces the dynamic form and is used to calculate combustor enthalpy such that

where

$$
h_{C B}=(h w)_{C B} / \dot{w}_{C B} \text {, out }
$$

$$
(h \dot{w})_{C B}=h_{C B, \text { in }}{ }^{\star} \dot{w}_{C B, \text { out }}+\dot{w}_{f} \star(n \star H V F)
$$

The combustor temperature is computed from a bivariate function of enthalpy and fuel-air ratio. This function is based on data containe's in the standard gas tables. 10 since no mixing of the flows occurs in the combustor discharge volume, a simple first order lag is used in place of the dynamic energy equation. The time constant is assumed to be equal to the ratio of the stored mass in the volume to the flow through the volume. Combustor pressure is calculated from the gas state Eq. (4).

In stall operation, the fuel-air mixture in the combustor becomes rich. This is due to the decrease in airflow from the compressor. Unburnt fuel remains after combustion. This causes a decrease in combustor efficiency. The stall combustor model computes degraded combustor efficiency as a function of fuel-air ratio. 
Turbines

The turbine models differ significantly from the models of previousiy reported engine simulations. Previous models have used overall steady-state performance maps for the turbines. Usualiy, a turbine speed parameter and a turbine pressure ratio are used to compute turbine flow and enthalpy drop parameters. In the present model, a technique described in Ref. 11 is used. The turbine flow parameter, tfp, and enthalpy drop parameter, thp, are computed from functions of turbine pressure ratio only. Adjustments are made to account for temperature effects. The general flow and enthalpy drop equations for the turbines are as follows

$$
\begin{gathered}
\left.\dot{\omega}_{T B}=(t f p) \star \delta_{T B}\right) / \sqrt{\theta_{T B}} \\
\Delta h_{T B}=\left(t h p \star{ }^{\theta_{T B}}\right)
\end{gathered}
$$

Cooling bleed for each turbine is assumed to re-enter the flow stream at the discharge of the turbine. The cooling bleeds do not perform any turbine work. The form of the energy equation for the turbines requires the calculation of enthalpies. As previously mentioned, the enthalpies are calculated as functions of temperature, neglecting the effect of fuel-air ratio. The form of the energy equation for the turbine volumes is

$$
\begin{array}{r}
\frac{d}{d t}\left[(W T)_{T B}\right]=\frac{1}{c_{V_{T B}}}\left[\sum\left(\dot{w}_{T B, i n} * h_{T B, i n}\right)\right. \\
\left.-h_{T B} * \sum \dot{w}_{T B, \text { out }}\right]
\end{array}
$$

Turbine pressure and temperature are calculated from the gas state $\mathrm{Eq}$. (4).

During stall, unburned fuel may enter the turbines with the possibiltiy for combustion. Depending on where the combustion takes place and on how the heat release affects the turbine work output, considerable model variation is possible. Results from various efforts to model this combustion process have not indicated that the process significantly affects simulation results. Because of the complexity of a turbine combustion model and the real-time constraint of this simulation, the turbine combustion process was not included in this model.

\section{Nozzles}

Based on available data, pressure losses in the bypass and the core ducts were assumed to be small. These pressure losses were lumped into the core and bypass nozzles. The nozzle flow coefficients were adjusted to provide the correct nozzle flows for the given pressure ratios. The general equation form used to calculate flow for the bypass and core nozzles is

$$
\dot{w}_{N}=\left(c d_{N}^{\prime} \star A_{N} * c f p_{N} * P_{N}\right) / \sqrt{T_{N}}
$$

The adjusted nozzle flow coefficient, $c d^{\prime} \mathrm{N}$, is fit as a function of nozzle pressure ratio. The nozzle flow parameter, cfpN, is calculated from

$$
\begin{aligned}
& c f p_{N}=\sqrt{\frac{2 g c}{R a}} * \sqrt{\frac{\gamma}{\gamma-I}} *\left[\left(\frac{P}{P_{N}}\right)\right]^{1 / \gamma} * \\
& \sqrt{1-\left[\left(\frac{P}{P_{N}}\right)\right]^{(\gamma-T / \gamma)}}
\end{aligned}
$$

Rotor Dynamics

The following general equations define the rotor dynamics for the high speed and low speed rotors.

$$
\begin{gathered}
\mathrm{d} / \mathrm{dt}(\mathrm{N})=(30 / \pi \mathrm{I}) \star\left(Q_{T B}-Q_{F C}\right) \\
Q_{T B}=(60 \star J / 2 \star \pi) \star\left(\Delta h_{T B} \star \dot{w}_{T B}\right) / N \\
Q_{F C}=(60 \star J / 2 \star \pi) \star\left(\left(h_{\text {out }}-h_{\text {in }}\right)_{F C}\right. \\
\left.\star \dot{w}_{F C}\right) / N
\end{gathered}
$$

Implementation

The engine model was programmed to run on one of the NASA Lewis Research Center's two hybrid computer systems (fig. 3). Each system consists of an Electronic Associates Inc. (EAI) PACER 600 hybrid computer and assorted peripherals. Each hybrid computer consists of one PACER 100 digital computer, two mode? 681 (or 680) analog consoles, and a model 693 hybrid interface. A multivariable function generation (MVFG) unit is available as a peripheral to the analog computers.

The TF34-GE-100 turbof an engine simulation uses two model 681 analog consoles, one model 680 analog console, and the MVFG unit. The consoles and the MVFG unit are connected to each other through the Central Trunking System. Figure 4 shows the computational breakdown among the three consoles. Some univariate functions are implemented using digitally controlled function generators, DCFG's that are available on the analog consoles.

To attain the real-time response of the simulation, the MVFG unit is used for bivariate function generation. Use of the digital computer for evaluation of bivariate functions required a time-scaling of the analog by a factor of 100 . The digital computer introduced a delay that prevented stable, real-time operation of the simulation. Because of the use of the MVFG's, the digital computer is not necessary for the simulation calculations. It is used for set up and check out of the analog consoles and MVFG unit prior to simulation operation.

The digital computer is also used to obtain listings of steady-state simulation data. A NASA developed software executive EXEC1 and an interactive data collection and display program INFORM12, 13 are used in the simulation. Selected engine variables are read into the digital computer via analog-to-digital converters, and are processed by INFORM. Guidelines for use of the EXECI and INFORM software are given in Ref. 13. 


\section{Concluding Remarks}

A full-range, real-time hybrid simulation of the TF34-GE-100 turbofan engine with post-stall capability is currently being developed. The engine model equations are based on data obtained from the engine manfacturer's steady-state digital simulation of this engine. Dynamic forms of the continuity, energy, and momentum equations have been added to provide the required transient capability. Where necessary, simplifications to the basic equations have been made to attain realtime response of the simulation. As of the writing of this paper, the out-of-stall simulation is running in real-time on the hybrid computer. The in-stall characteristics for the fan and compressor have been incorporated into the simulation and are being checked out. Once the simulation is fully operational, it will be validated by experimental data from engine stall tests that are planned. Eventually this simulation will be used to test and evaluate various stall recovery control schemes that are now under development.

\section{References}

1. Wenzel, L. M., and Bruton, W. M., "Analytical Investigation of Nonrecoverable Stali, " NASA TM-82792, 1982.

2. Szuch, J. R., Soeder, J. F., Seldner, K., and Cwynar, D. S., "F100 Multivariable Control Synthes is Program: Evaluation of a Multivariable Control Using a Real-Time Engine Simulation," NASA TP-1056, 1977.

3. Day, I. J., Greitzer, E. M., and Cumpsty, N. A., "Prediction of Compressor Performance in Rotating Stall," Journal of Engineering for Power, vol. 100 , no. 1, Jan. 1978, pp. 1-14.
4. Greitzer, E. M., "Surge and Rotating Stall in Axial Flow Compressors, I: Theoretical Compressor System Mode1," ASME Paper 75-GT-9, Mar. 1975.

5. Greitzer, E. M., "Surge and Rotating Stall in Axial Flow Compressors, II. Experimental Results and Comparison with Theory," ASME Paper 75-GT-10, Mar. 1975.

6. Szuch, J. R., and Bruton, W. M., "Real-Time Simulation of the TF30-P-3 Turbofan Engine Using a Hybrid Computer," NASA TM X-3106, 1974.

7. Szuch, J. R., and Seldner, K., "Real-Time Simulation of F100-PW-100 Turbofan Engine Using the Hybrid Computer," NASA TM X-3261, 1975.

8. Szuch, J. R., Seldner, K. and Cwynar, D. S., "Development and Verification of Real-Time Hybrid Computer Simulation of F100-PW-100(3) Turbofan Engine," NASA TP-1034, 1977.

9. "Instruction Manual for Computer Program TF34/74018/," General Electric Company SAO Memo 74SC18, Aug. 31, 1974.

10. Keenan, J. H., and Kaye, J. A., Gas Tables. John Wiley, New York, 1948.

11. Glassman, A. J., "Turbine Design and Application," vol. I, NASA SP-290, 1972.

12. Cwynar, D. S., "INFORM: An Interactive Data Collection and Display Program With Debugging Capability," NASA TP-1424, 1980.

13. Bruton, W. M., and Cwynar, D. S., "Lewis Hybrid Computing System, Users Manual," NASA TM-79111, 1979. 


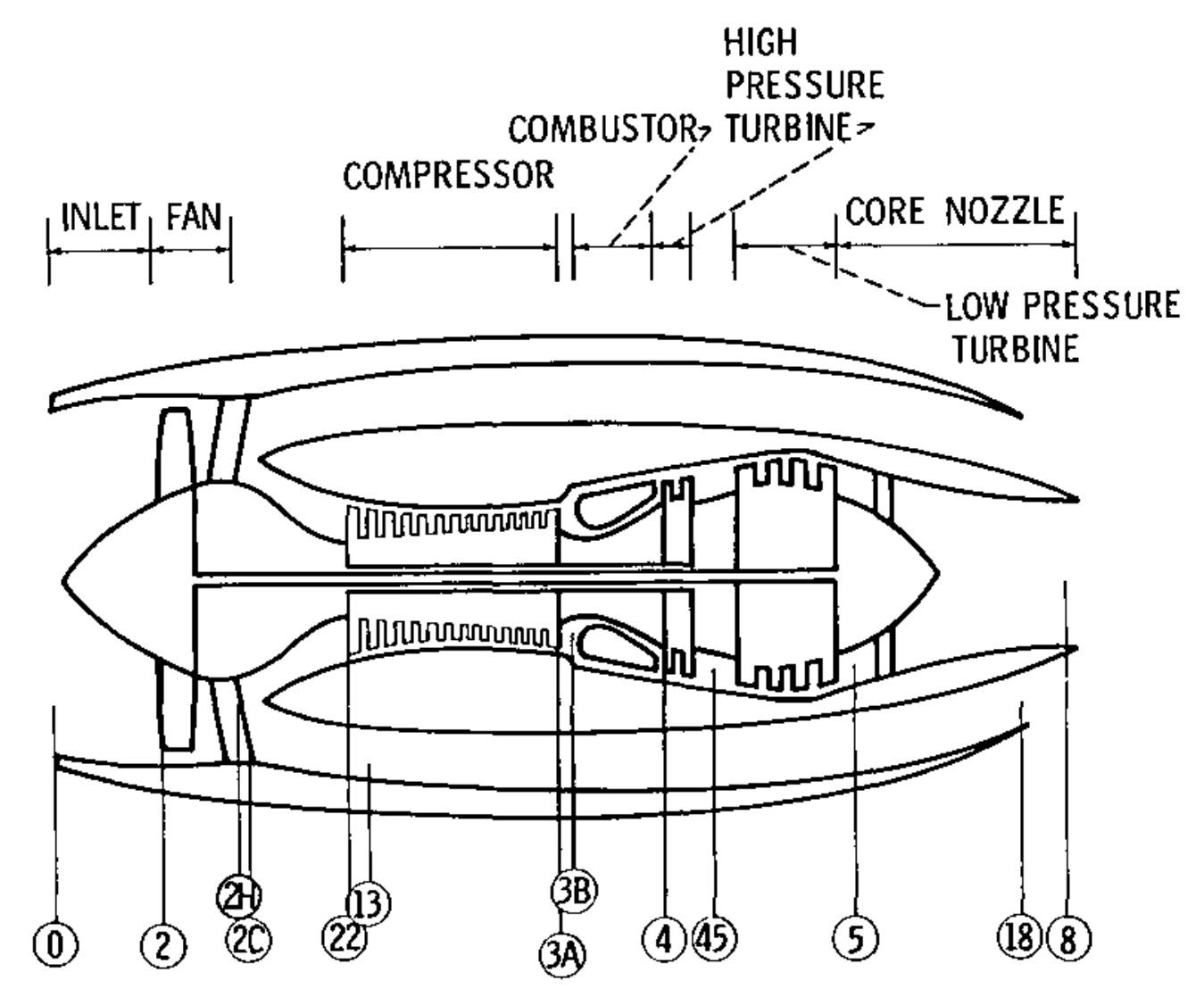

Figure 1. - TF34-GE-100 turbofan engine schematic. 


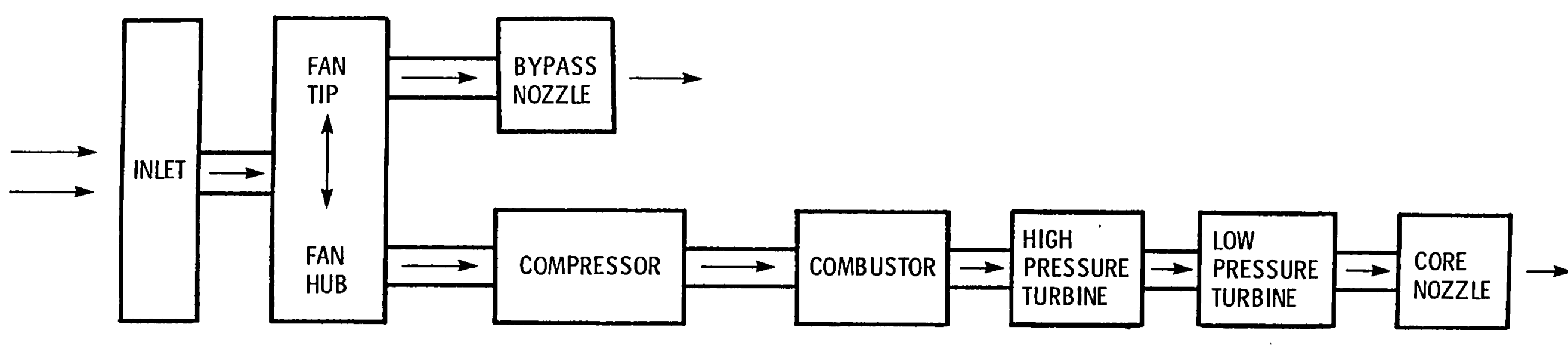

(a) Normal engine airflow.

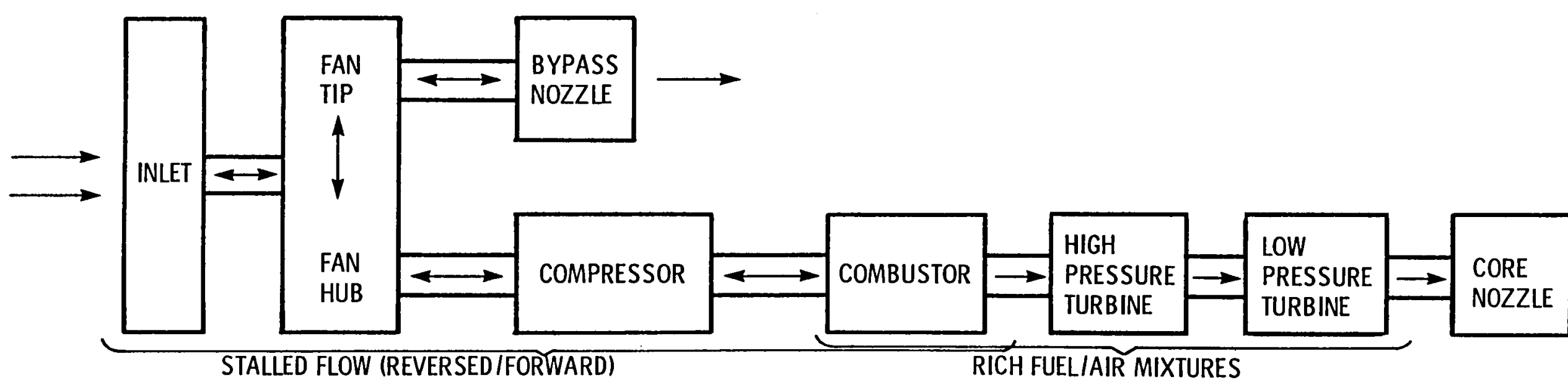

(b) Stalled engine airflow.

Figure 2. - Flow diagram. 


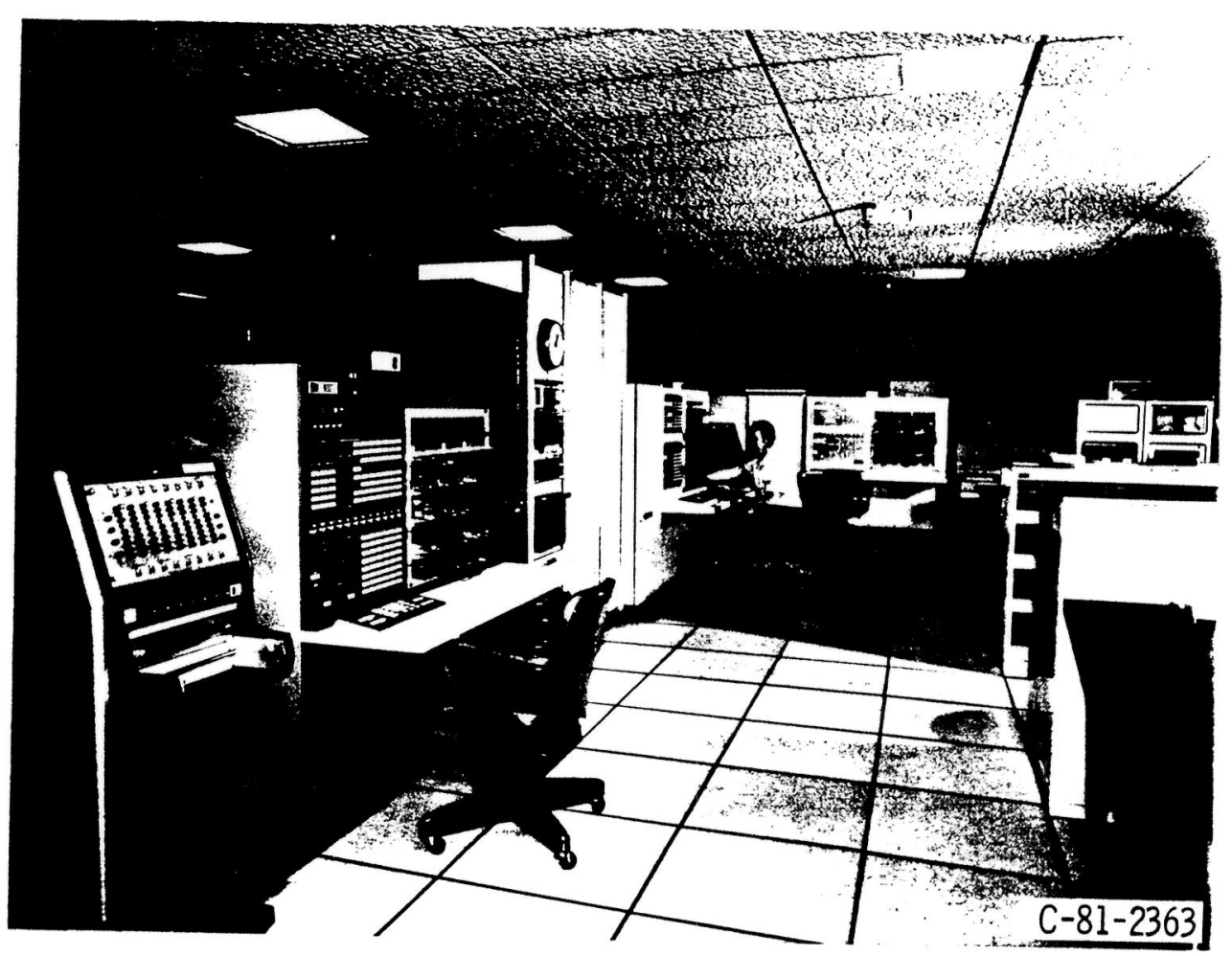

Figure 3. - NASA Lewis Research Center hybrid computer facility. 


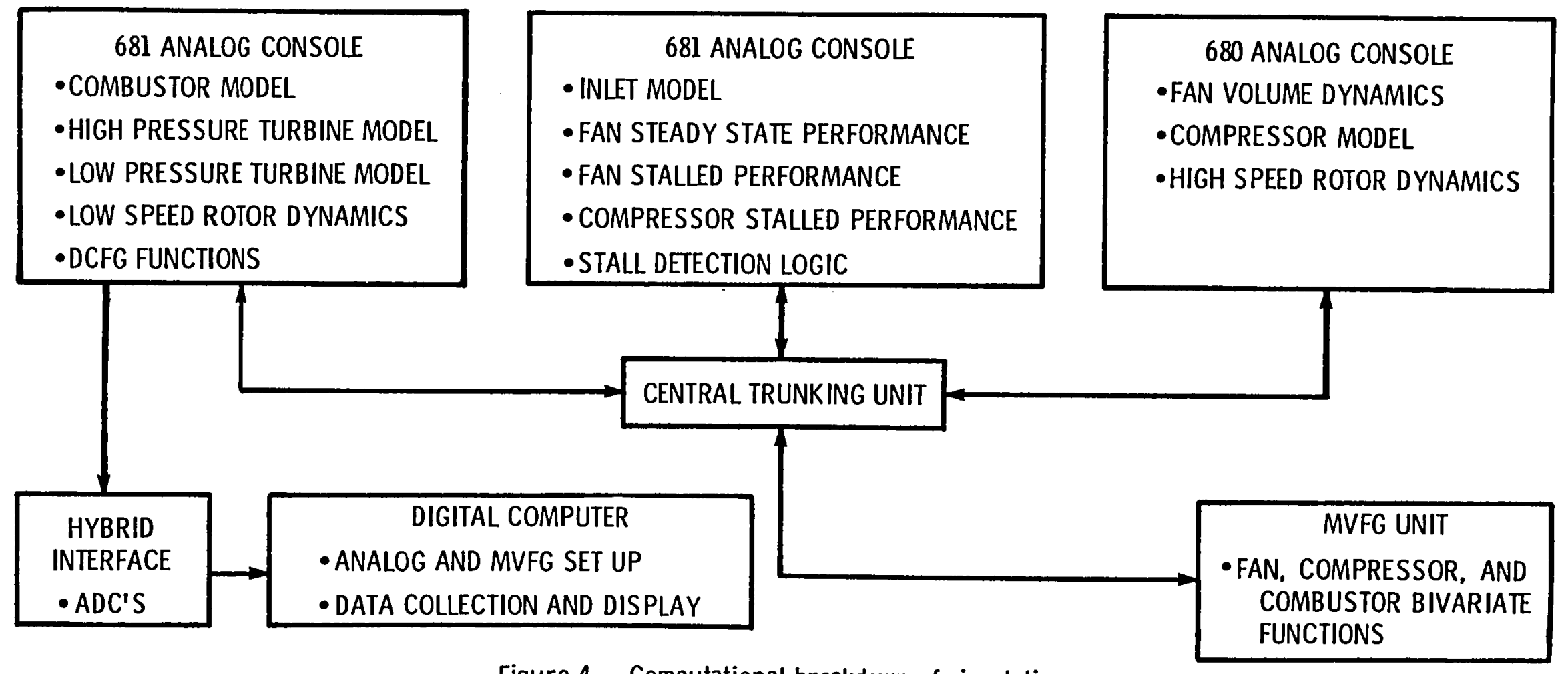

Figure 4. - Computational breakdown of simulation. 


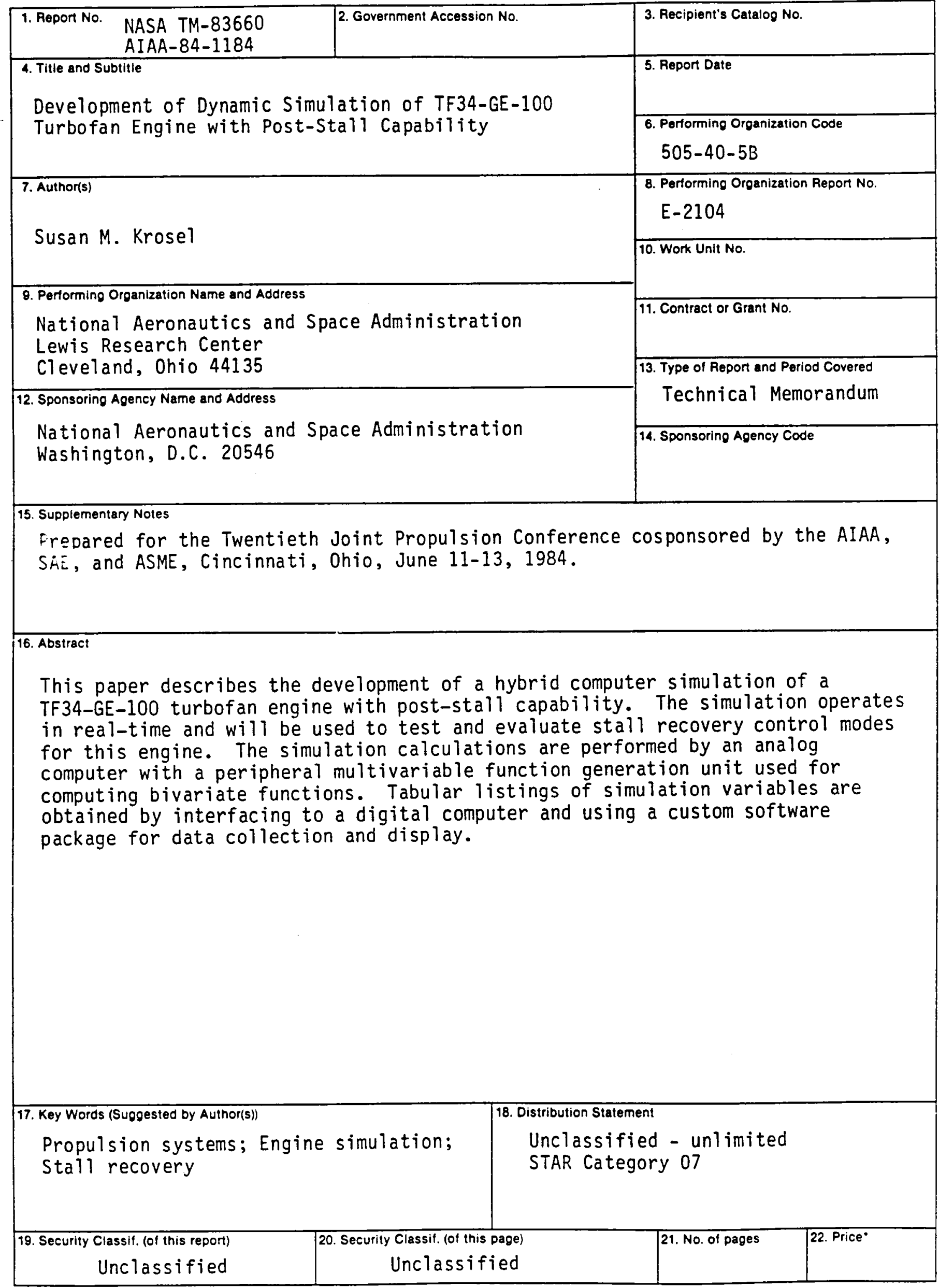

-For sale by the National Technical Information Service. Spsingfield. Virginia 22161 